\title{
Definition and formula of substance content change in marine bay and the application
}

\author{
Dongfang Yang ${ }^{1,2,4, a}$, Danfeng Yang ${ }^{3}$, Fengyou Wang ${ }^{1,2}$, Sixi Zhu ${ }^{1,2}$ and Xiuqin \\ Yang ${ }^{1,2}$ \\ ${ }^{1}$ Research Center for Karst Wetland Ecology, Guizhou Minzu University, Guizhou Guiyang, \\ Guizhou Guiyang, China \\ ${ }^{2}$ College of Chemistry and Environmental Science, Guizhou Minzu University, Shanghai, 550025, \\ China \\ ${ }^{3}$ College of Information Science and Engineering, Fudan University, Shanghai, 200433, China \\ ${ }^{4}$ North China Sea Environmental Monitoring Center, SOA, Qingdao 266033, China \\ adfyang_dfyang@126.com
}

Keywords: Horizontal loss amount, Vertical dilution amount, Vertical sedimentation amount, Definition, Formula, Marine bay.

\begin{abstract}
We analyzed the substance content change in marine based on water exchange, and provided definitions and formulas for horizontal loss amount, vertical dilution amount and vertical sedimentation amount. A case study in analysis the change of $\mathrm{Pb}$ contents in Jiaozhou Bay was provided to exhibit the application of these definitions and formulas. Results showed that the vertical variation and model of $\mathrm{Pb}$ contents could be revealed by means of the definitions and formulas. The horizontal loss amount of $\mathrm{Pb}$ indicated the $\mathrm{Pb}$ was very difficult to be imported from the open sea to the bay via the bay channel. The vertical dilution and sedimentation loss amount of $\mathrm{Pb}$ indicated that $\mathrm{Pb}$ was diluted greatly in the bay mouth due to the marine current, and the sedimentation rate was relative high in the open waters outside the bay mouth.
\end{abstract}

\section{Introduction}

$\mathrm{Pb}$ has been widely used in instrumentation, electrolysis and smelting etc. A large amount of $\mathrm{Pb}$-containing wastes were generated and discharged to the environment since industrial revolution. However, $\mathrm{Pb}$ is high toxicity and long persistent, and many marine bays have been polluted by $\mathrm{Pb}$ finally due to ocean is the sink of various pollutants [1-6]. Therefore, understanding of the transfer process of various pollutants in marine bay is essential to environmental protection.

In this paper, we analyzed the substance content change in marine based on water exchange, and provided definitions and formulas for horizontal loss amount, vertical dilution amount and vertical sedimentation amount. Jiaozhou Bay is a semi-closed bay located in Shandong Province, China. A case study in analysis the change of $\mathrm{Pb}$ contents in Jiaozhou Bay was provided to exhibit the application of these definitions and formulas.

\section{Materials and method}

Basic definition. Along with the water exchange, the contents of the substances in marine bay are decreasing continuously [10-12]. Once the substances are mainly from point-source, the contents are very high. By means of water exchange, it is necessary to define the horizontal loss amount of the substance, including absolute horizontal loss amount and relative horizontal loss amount. By means of gravity force and marine current, the substances were settling to sea bottom continuously, and it is necessary to define the vertical dilution amount and vertical sedimentation amount, including absolute vertical dilution amount and vertical sedimentation amount, as well as relative vertical dilution amount and vertical sedimentation amount.

Definition and formula of horizontal loss. In surface waters, suppose that the content of 
certain substance $(M)$ outside the bay mouth is $A$, in the bay mouth is $B$, and inside the bay mouth is $C$. From the open waters to the inside of the bay, the absolute horizontal loss amount is $D$, and the relative horizontal loss amount is $E$. If $D<0$, the absolute horizontal loss amount is $-D$ (Eq. 1 ). From inside of the bay to the open waters, the absolute horizontal loss amount is $F$, and the relative horizontal loss amount is $G$. If $G<0$, the absolute horizontal loss amount is $-F$ (Eq. 2).

$$
\begin{array}{rlrl}
D=A-B, & E & =|A-B| / \max (A, B) \\
F=B-C, & G=|B-C| / \max (B, C)
\end{array}
$$

In bottom waters, suppose that the content of certain substance $(M)$ outside the bay mouth is $a$, in the bay mouth is $b$, and inside the bay mouth is c. From the open waters to the inside of the bay, the absolute horizontal loss amount is $d$, and the relative horizontal loss amount is $e$. If $d<0$, the absolute horizontal loss amount is $-d$ (Eq. 3). From inside of the bay to the open waters, the absolute horizontal loss amount is $f$, and the relative horizontal loss amount is $g$. If $f<0$, the absolute horizontal loss amount is $-f$ (Eq. 4).

$$
\begin{array}{ll}
d=a-b, & e=|a-b| / \max (a, b) \\
f=b-c, & g=|b-c| / \max (b, c)
\end{array}
$$

Definition and formula of vertical loss. In waters outside the bay, suppose that the content of certain substance $(M)$ in surface waters is $A$, while in bottom waters is $a$. For a sampling site $n$, the absolute vertical dilution amount is $V_{n a}$, and the relative vertical dilution amount is $V_{n r}$. If $V_{n a}<0$, the absolute vertical sedimentation amount is $-V_{n a}$. If $V_{n a}>0$, the relative vertical dilution amount is $V_{n r}$ (Eq. 5).

$$
V_{n a}=A-a, \quad V_{n r}=|A-a| / \max (A, a)
$$

Case study. Jiaozhou Bay is located in the south of Shandong Province, eastern China $\left(35^{\circ} 55^{\prime}-36^{\circ} 18^{\prime} \mathrm{N}, 120^{\circ} 04^{\prime}-120^{\circ} 23^{\prime} \mathrm{E}\right)$, which is connected to the Yellow Sea in the south. This bay is a typical of semi-closed bay, and the total area, average water depth and bay mouth width are 446 $\mathrm{km}^{2}, 7 \mathrm{~m}$ and $3 \mathrm{~km}$, respectively. There are a dozen of rivers, and the majors are Dagu River, Haibo Rriver, Licun Rriver, and Loushan Rriver etc., all of which are seasonal rivers [7-8]. The investigation on Cd in Jiaozhou Bay was carried on in April, July and Pctober 1986 in three investigation sites namely 2031, 2032 and 2033, respectively (Fig. 1). Pb in waters was sampled and monitored follow by National Specification for Marine Monitoring [9].

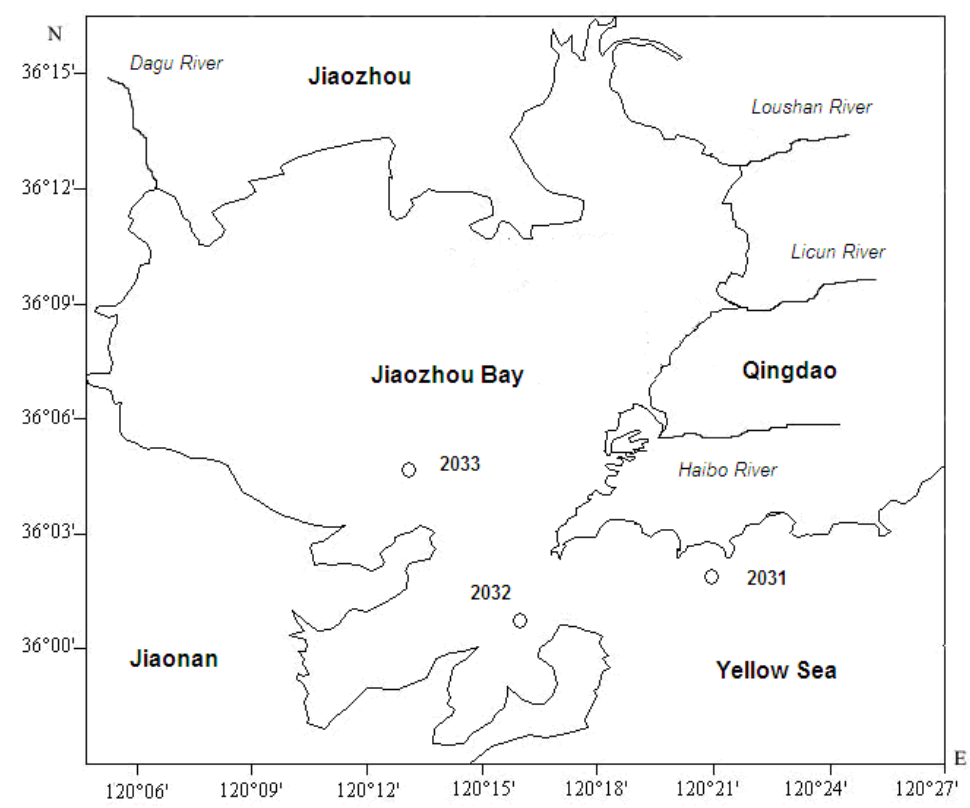

Fig. 1 Geographic location and sampling sites in Jiaozhou Bay 


\section{Results}

Horizontal loss. Suppose that waters from the open waters to the bay mouth is from $A$ to $B$, and waters from the bay mouth to the inside of the bay is from $B$ to $C$. Pb contents in surface waters were changing a lot along with time, and the horizontal losses in surface waters could be calculated by Eq. 1 and Eq. 2, and were listed in Table 1. Similarly, the horizontal losses in bottom waters could be calculated by Eq. 3 and Eq. 4, and were listed in Table 2.

Table 1 Horizontal losses of $\mathrm{Pb}$ in surface waters

\begin{tabular}{|c|c|c|c|}
\hline$A$ to $B$ & $D$ & $E$ & $E$ \\
\hline April & 12.97 & 0.50664 & $50.66 \%$ \\
\hline July & -7.35 & 0.21054 & $21.05 \%$ \\
\hline October & 0.1 & 0.00365 & $0.36 \%$ \\
\hline$B$ to $C$ & $F$ & $G$ & $G$ \\
\hline April & -2.45 & 0.16247 & $16.25 \%$ \\
\hline July & 4.82 & 0.16018 & $16.02 \%$ \\
\hline October & 6.93 & 0.25384 & $25.38 \%$ \\
\hline
\end{tabular}

Table 2 Horizontal losses of $\mathrm{Pb}$ in bottom waters

\begin{tabular}{|c|c|c|c|}
\hline$A$ to $B$ & $d$ & $e$ & $e$ \\
\hline April & 2.15 & 0.11832 & $11.83 \%$ \\
\hline July & -0.66 & 0.02887 & $2.89 \%$ \\
\hline October & 2.36 & 0.06662 & $6.66 \%$ \\
\hline$B$ to $C$ & $f$ & $g$ & $g$ \\
\hline April & 4.72 & 0.29463 & $29.46 \%$ \\
\hline July & -11.47 & 0.50175 & $50.17 \%$ \\
\hline October & 10.58 & 0.32002 & $32.00 \%$ \\
\hline
\end{tabular}

Vertical dilution amount and sedimentation amount. Pb contents in surface waters were changing a lot along with time, and the vertical dilution amount and sedimentation amount could be calculated by Eq. 5, and were listed in Table 3. For the three sampling sites (Site 2031, 2032 and 2033), Pb contents in surfaces were subtracting by which in bottom waters in different months. The subtractions in April, July and October were ranging from -2.88 to $17.10 \mu \mathrm{g} \mathrm{L}^{-1},-3.39$ to $7.43 \mu \mathrm{g}$ $\mathrm{L}^{-1}$ and -8.02 to $-2.11 \mu \mathrm{g} \mathrm{L}{ }^{-1}$, respectively. In April, the subtraction in Site 2032 was negative, yet in the other sampling sites was positive (Table 4). In July, the subtraction in Site 2033 was negative, yet the subtractions in the other two sampling sites were positive (Table 4). In October, the subtractions in all of the three sampling sites were negative (Table 4).

Table 3 Vertical dilution amount and sedimentation amount of $\mathrm{Pb}$

\begin{tabular}{|c|c|c|c|c|}
\hline Time & Waters & $V_{n a}$ & $V_{n r}$ & $V_{n r}$ \\
\hline April & Outside the bay & 7.43 & 0.29023 & $29.02 \%$ \\
\cline { 2 - 5 } & Bay mouth & -3.39 & 0.21161 & $21.16 \%$ \\
\cline { 2 - 5 } & Inside the bay & 3.78 & 0.25066 & $25.06 \%$ \\
\hline \multirow{3}{*}{ July } & Outside the bay & 5.36 & 0.19448 & $19.44 \%$ \\
\cline { 2 - 5 } & Bay mouth & 12.05 & 0.34517 & $34.51 \%$ \\
\cline { 2 - 5 } & Inside the bay & -4.24 & 0.12351 & $12.35 \%$ \\
\hline October & Outside the bay & -8.02 & 0.22643 & $22.64 \%$ \\
\cline { 2 - 5 } & Bay mouth & -5.76 & -0.17423 & $17.42 \%$ \\
\cline { 2 - 5 } & Inside the bay & -2.11 & -0.09386 & $9.38 \%$ \\
\hline
\end{tabular}

Table $4 \mathrm{~Pb}$ contents in surface minus which in bottom waters

\begin{tabular}{|c|c|c|c|}
\hline Time & Site 2033 & Site 2032 & Site 2031 \\
\hline April & Positive & Negative & Positive \\
\hline July & Negative & Positive & Positive \\
\hline October & Negative & Negative & Negative \\
\hline
\end{tabular}




\section{Discussion}

Substance content's change. The contents of the substances were changing greatly during the migration processes. Based on the vertical water's effect and horizontal water's effect [11-12], the horizontal changes were revealing the loss effect of horizontal water body, and the changes of surface and bottom waters were revealing the dilution effect and sedimentation effect. Hence, based on the water's effect, we further provided the definitions and formulas of substances, as well as the vertical changes. Therefore, the migration processes of the substances were quantified.

Horizontal and vertical change. In open waters outside the bay mouth, $\mathrm{Pb}$ was mainly sourced from marine current. In waters inside the bay mouth, $\mathrm{Pb}$ was mainly sources from stream flow. In waters in the bay mouth, $\mathrm{Pb}$ contents were decreasing from the high value region to low value region by tide and marine current. In April, from the open waters to the bay mouth, the horizontal loss of $\mathrm{Pb}$ in surface waters was biggest as $50.66 \%$, yet in bottom waters as smallest as $11.83 \%$ (Fig. 2). The vertical dilution amounts of $\mathrm{Pb}$ were relative big in waters outside the bay mouth and waters inside the bay mouth, while in waters in the bay mouth the vertical sedimentation amount was relative small. In July, from the bay mouth to the inside of the bay, the horizontal loss of $\mathrm{Pb}$ in bottom waters was biggest as $50.17 \%$. From the open water s to the bay mouth the horizontal loss of $\mathrm{Pb}$ in bottom waters as smallest as $2.89 \%$ (Fig. 3 ). In waters outside the bay mouth and waters inthe bay mouth, the vertical dilution amounts of $\mathrm{Pb}$ were relative big, while in waters inside the bay mouth, the vertical sedimentation amount was relative small. In October, from the waters inside the bay mouth to the bay mouth, the horizontal loss of Pb in surface waters was biggest as $32.00 \%$, yet in bottom waters as smallest as $11.83 \%$ (Fig. 4). In waters outside the bay mouth, waters inside the bay mouth and waters in the bay mouth, there were vertical sedimentations.

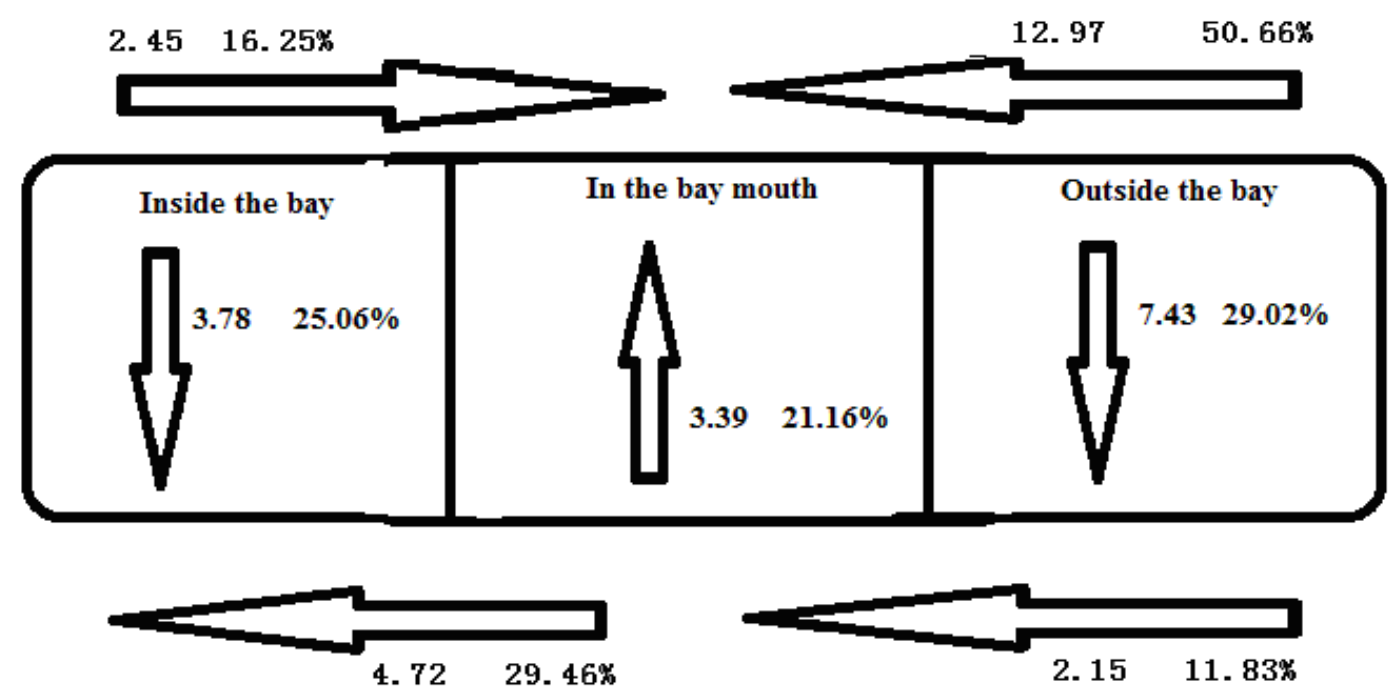

Fig. 2 The model of the horizontal and vertical changing of $\mathrm{Pb}$ in April

In generally, the absolute horizontal loss of $\mathrm{Pb}$ in April, July and October 1986 was from $0.10-12.97 \mu \mathrm{g} \mathrm{L} \mathrm{L}^{-1}$, while the relative horizontal loss was $0.36-50.66 \%$. The absolute vertical sedimentation of $\mathrm{Pb}$ was 3.39-8.02 $\mu \mathrm{g} \mathrm{L}^{-1}$, while the relative horizontal sedimentation was 9.38-22.64\%. The absolute vertical dilution of $\mathrm{Pb}$ was 3.78-12.05 $\mu \mathrm{g} \mathrm{L}^{-1}$, while the relative horizontal dilution was $19.44-34.51 \%$. In according to the horizontal loss of $\mathrm{Pb}$, it could be found that from the open waters to the bay mouth and from the bay mouth to the inside of the bay, the horizontal loss amount was biggest during the extension process. In surface waters, the horizontal loss of $\mathrm{Pb}$ was almost $50 \%$ during the extension process from the open waters to the bay mouth. In bottom waters, the horizontal loss of $\mathrm{Pb}$ was almost 50\% during the extension process from the bay mouth to the inside of the bay. Hence, $\mathrm{Pb}$ was very difficult to be imported form the open waters to the inner bay via bay channel. The Pb source strength of marine current was $25.60-27.40 \mu \mathrm{g} \mathrm{L}^{-1}$, which was very stable yet relative low. The vertical dilution amount and vertical sedimentation 
amount of $\mathrm{Pb}$ were revealing that the relative vertical dilution amount of $\mathrm{Pb}$ was biggest in the bay mouth, while the relative vertical sedimentation amount of $\mathrm{Pb}$ was biggest in waters outside the bay mouth. In waters in the bay mouth, $\mathrm{Pb}$ was diluted greatly by means of tide and marine current, while the sedimentation of $\mathrm{Pb}$ was relative great in waters outside the bay mouth.

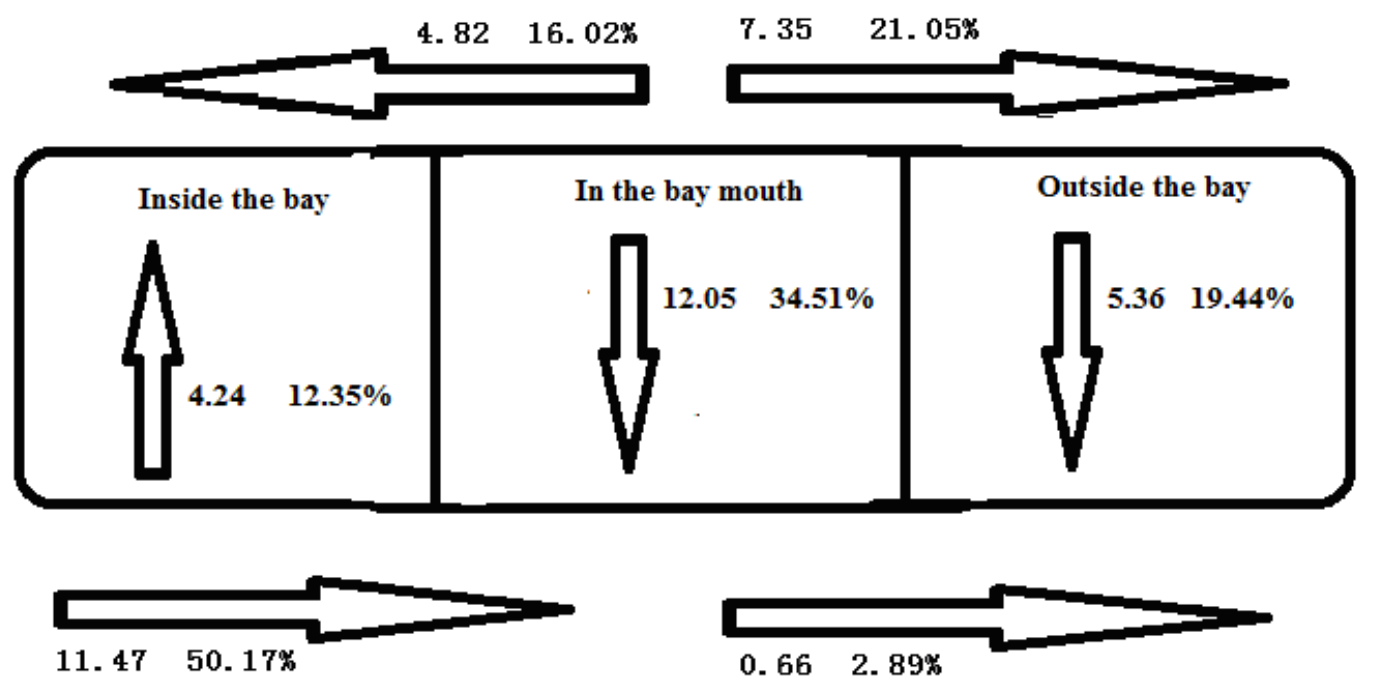

Fig. 3 The model of the horizontal and vertical changing of $\mathrm{Pb}$ in July

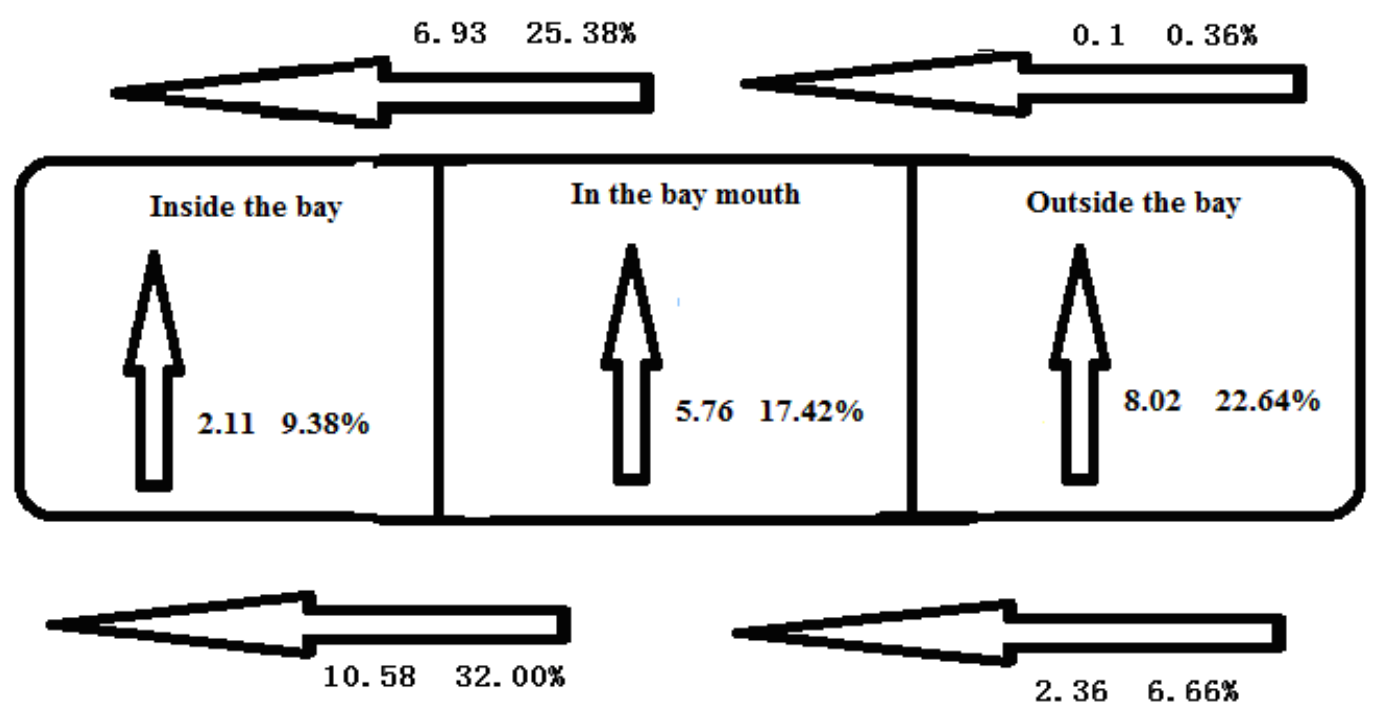

Fig. 4 The model of the horizontal and vertical changing of $\mathrm{Pb}$ in October

Regional settling. At regional scale, for the three sampling sites (Site 2031, 2032 and 2033), $\mathrm{Pb}$ contents in surfaces were subtracting by which in bottom waters in different months, and the subtractions were changing along with time, and were indicating the changing of $\mathrm{Pb}$ contents in surface and bottom waters. Once $\mathrm{Pb}$ was imported to the bay, it was originally arrived at surface waters, and was settling to sea bottom rapidly and continuously, and was exhibiting the changing of $\mathrm{Pb}$ contents in surface and bottom waters. In April, $\mathrm{Pb}$ was mainly sourced from marine current, and $\mathrm{Pb}$ contents in surface waters were higher than which in bottom waters in waters inside and outside the bay mouth, yet $\mathrm{Pb}$ contents in surface waters were lower than which in bottom waters in waters in the bay mouth. It was revealing that the relative high $\mathrm{Pb}$ contents were extending from the inside and outside of the bay mouth to the bay mouth. In July, Pb was mainly sourced from stream flow, and the source strength was relative high. Hence, the was a large sedimentation amount in waters inside the bay mouth, resulting in Pb contents in surface waters were lower than which in bottom waters. However, in waters in the bay mouth and outside the bay mouth, $\mathrm{Pb}$ contents in surface 
waters were high than which in bottom waters. It was revealing that the relative high $\mathrm{Pb}$ contents were extending along with the surface waters and there was high sedimentation in waters inside the bay mouth. In October, Pb was mainly sourced from stream flow and marine current, and the source strength was relative high. Hence, $\mathrm{Pb}$ contents in surface waters were lower than which in bottom waters in waters inside and outside the bay mouth, as well as in the bay mouth. It was revealing that the relative high $\mathrm{Pb}$ contents were extending and there were high sedimentations in waters inside and outside the bay mouth, as well as in the bay mouth. In generally, in April, July and October, the continuously sedimentation of $\mathrm{Pb}$ was resulting in the great accumulation of $\mathrm{Pb}$ in sea bottom. Hence, in October, Pb contents in surface waters were lower than which in bottom waters in waters inside and outside the bay mouth, as well as in the bay mouth.

\section{Conclusions}

We analyzed the substance content change in marine based on water exchange, and provided definitions and formulas for horizontal loss amount, vertical dilution amount and vertical sedimentation amount. A case study in analysis the change of $\mathrm{Pb}$ contents in Jiaozhou Bay was provided to exhibit the application of these definitions and formulas.

From the open waters to the bay mouth and from the bay mouth to the inside of the bay, the horizontal loss amount was biggest during the extension process. In surface waters, the horizontal loss of $\mathrm{Pb}$ was almost $50 \%$ during the extension process from the open waters to the bay mouth. In bottom waters, the horizontal loss of $\mathrm{Pb}$ was almost 50\% during the extension process from the bay mouth to the inside of the bay. Hence, $\mathrm{Pb}$ was very difficult to be imported form the open waters to the inner bay via bay channel.

The vertical dilution amount and vertical sedimentation amount of $\mathrm{Pb}$ were revealing that the relative vertical dilution amount of $\mathrm{Pb}$ was biggest in the bay mouth, while the relative vertical sedimentation amount of $\mathrm{Pb}$ was biggest in waters outside the bay mouth. In waters in the bay mouth, $\mathrm{Pb}$ was diluted greatly by means of tide and marine current, while the sedimentation of $\mathrm{Pb}$ was relative great in waters outside the bay mouth.

In April, July and October, the continuously sedimentation of $\mathrm{Pb}$ was resulting in the great accumulation of $\mathrm{Pb}$. Hence, in October, $\mathrm{Pb}$ contents in surface waters were lower than which in bottom waters in waters inside and outside the bay mouth, as well as in the bay mouth.

\section{Acknowledgement}

This research was sponsored by Doctoral Degree Construction Library of Guizhou Nationalities University, Education Ministry's New Century Excellent Talents Supporting Plan (NCET-12-0659), the China National Natural Science Foundation (31560107), Major Project of Science and Technology of Guizhou Provincial ([2004]6007-01), Guizhou R\&D Program for Social Development ([2014] 3036) and Research Projects of Guizhou Nationalities University ([2014]02), Research Projects of Guizhou Province Ministry of Education (KY [2014] 266), Research Projects of Guizhou Province Ministry of Science and Technology (LH [2014] 7376).

\section{References}

[1] Yang D F, Su C, Gao Z H, et al.: Chin. J. Oceanol. Limnol., Vol. 26(2008): 296-299.

[2] Yang DF, Guo JH, Zhang YJ, et al.: Journal of Water Resource and Protection, Vol. 3(2011): 41-49.

[3] Yang DF, Zhu SX, Wang FY, et al.: Applied Mechanics and Materials, Vol. 651-653(2014), p. 1419-1422.

[4] Yang DF, Geng X, Chen ST, et al.:Applied Mechanics and Materials, Vol. 651-653 (2014), p. 1216-1219. 
[5] Yang DF, Ge HG, Song FM, et al.: Applied Mechanics and Materials, Vol. 651-653 (2014), p. 1492-1495.

[6] Yang DF, Zhu SX, Wang FY, et al.:Applied Mechanics and Materials, Vol.651-653 (2014), p. 1292-1294.

[7] Yang DF, Chen Y, Gao ZH, Zhang J, et al.:Chinese Journal of Oceanology and Limnology, Vol. 23(2005): 72-90.

[8] Yang DF, Wang F, Gao ZH, et al.: Marine Science, Vol. 28 (2004), p.71-74.

[9] State Ocean Administration. The specification for marine monitoring: Beijing, Ocean Precess, (1991).

[10]Yang DF, Wang FY, He HZ, et al.: Proceedings of the 2015 international symposium on computers and informatics, Vol. (2015), p. 2655-2660.

[11]Yang DF, Miao ZQ, Xu HZ, et al.: Marine Environmental Science, Vol. 32 (2013), p. 373-380.

[12] Yang DF, Wang FY, Zhao XL, et al.:Sustainable Energy and Enviroment Protection, Vol. (2015), p. 191-195. 